\title{
Hidden Assumptions and their Influence on Clinicians' acceptance of new IT systems in the NHS
}

Senaka Fernando, Brunel University, senaka.fernando @brunel.ac.uk Jyoti Choudrie, University of Hertfordshire,j.choudrie@ @erts.ac.uk Mark Lycett, Brunel University, mark.lycett@brunel.ac.uk Sergio DeCesare, Brunel University, sergio.decesare @brunel.ac.uk

\section{ABSTRACT}

The UK National Health Service (NHS) is embarking on the largest investment programme in Information Technology (IT). The National Programme for IT (NPfIT) in the NHS is the biggest civil IT project in the world and seeks to revolutionise the way care is delivered, drive up quality and make more effective use of resources of the NHS. Despite these high expectations, the NHS has historically experienced some high profile IT failures and the sponsors of the programme admitted that there remain a number of critical barriers to the implementation of the programme. The clinicians' reluctance to accept new IT systems at a local level is seen to be a major factor in this respect. Focusing on such barriers, this paper reports a research that explored and explained why such reluctance occurs in the NHS. The main contribution of this research derives from the distinctive approach based on Kelly's Personal Construct Theory (PCT) to understand the 'reluctance'. The argument presented in the paper indicates that such reluctance should be viewed not as deliberate resistance imposed by clinicians, but as their inability of changing their established group personal constructs related to information systems development and delivery (ISDD) activities. So, this paper argues that the means which could take to reduce the 'reluctance' are therefore be creative rather than corrective or normative. The research took place in a NHS Trust and the paper pays considerable attention to technological, behavioural and clinical perspectives that emerged from the study. The research was conducted as a case study in a NHS trust and data was collected from two local NHS IT project. The main research participants in this study were: (a) IT professionals including IT project managers and senior IT managers; and (b) senior clinicians.

Keywords: Healthcare information systems development and delivery, National Health Service, reluctance, cognitions, personal constructs theory 


\section{INTRODUCTION}

In 1998, the National Health Service (NHS) recognised that Information Technology (IT) had a major role to play in healthcare, and Information for Health (NHS 1998) defined the strategic approach for the use of IT. As a consequence, the biggest investment programme in IT and infrastructure development in the NHS has been launched with $£ 6$ billion of funding and a centralised programme of procurements (Brennan 2005; Bourn 2006). The National Programme for IT (NPfIT) is the biggest civil IT project in the world and seeks to revolutionise the way health care is delivered, drive up quality and make more effective use of resources of the NHS (Hendy, Reeves et al. 2005). The aim of this programme is to use IT to give patients more choice whilst providing health professionals more efficient access to information and thereby ensure delivery of better patient care. The NPfIT (also now called Connecting for Health) promises not only to deliver a twenty-first century health service but also to create a wider change programme within the NHS (NAO 2008).

Despite these high expectations, the NHS has historically seen some high-profile IT failures (such as the Wessex Health Authority and London Ambulance Service cases). Indeed IT failures are still happening in the NHS. For example, the National Audit Office (NAO) in the UK reports that the original times scale for the Electronic Care Record Service, one of the central elements of the NPfIT, will be unachievable, putting confidence in the programme at risk. The NAO says that the Electronic Care Record Service can not be fully implemented until 2014-15, four years later than planned. The estimated cost for the NPfIT will be $£ 12.7$ billion, $£ 6.7$ billion higher than planned (NAO 2008).

So unsurprisingly, the ambitious nature of the NPfIT has raised many concerns among healthcare professionals and clinicians in the NHS who fear that NPfIT project could be another failure (see Hendy, Reeves et al. 2005; Hendy, Fulop et al. 2007). Indeed, the champions of the programme admit that there remain a number of critical barriers to the effective use of IT as a strategic tool in providing patient centred delivery of care and services for the NHS users (NHS 2003 August; NHS 2003 September). The reluctance of clinicians to accept the new IT systems at a local level is seen to be a major factor in this respect. It is claimed, for example, that the NPfIT will be a 
genuine success if clinicians in the NHS use the new systems and use them because they are unequivocally beneficial to them and the care of their patients (NHS 2003; NHS 2003; Bourn 2006). Some NHS top executives argue that this will be hard to achieve (see Collins 2003). These problems are well documented in the literature related to health information systems. For example, clinicians' reluctance to use the new IT systems, or their inability of using them in a way that the sponsors of NPfIT expect, as well as to capture anticipated benefits, are seen as major barriers to the successful use of new IT systems in the NHS (see Bend 2004; Hendy, Fulop et al. 2007).

Although researchers in the health informatics field have not paid much attention to clinicians' reluctance to use new IT systems in the NHS, they have taken considerable attempts to address similar issues in other health care organisations (see Schuster, Hall et al. 2003; Berner, Detmer et al. 2005; Scott, Rundall et al. 2005; Lapointe and Rivard 2006). Their research shows that there is a general consensus among researchers in the health informatics field that clinicians are reluctant to use variety of health information systems, even though their potential benefits have been repeatedly demonstrated. However most researchers in health informatics use the rationalist approach in their studies and consequently find difficult to investigate a variety of human and contextual factors that affect system acceptance by clinicians in actual use. In addition there is little theoretical discussion to understand why clinicians are reluctant to use health information systems (see Kaplan 2001).

Nevertheless there are several attempts in IS research that draw on theory for understanding similar issues in business organisations. Such attempts conceptualise "reluctance" in terms of user resistance (see Keen 1981; DeSanctis and Courtney 1983; Markus 1983; Joshi 1991). For instance Markus (1983) puts forward that people will be inclined to use a system if they believe it will support their position of power within the organisation. If they think it might cause them to lose power, they will resist. Indeed these researchers' theoretical explanations can shred some light on the phenomenon of "reluctance". However such explanations also pose many limitations as they portray people's behaviour in organisations as the primary 
dimension of "reluctance", without paying sufficient attention to people's cognition which ultimately influences such behaviour. The term cognition refers to the assumptions, expectations and knowledge that people use to understand organisational activities such as development and usage of IT systems. Bartunek and Moch (1987) argue that such cognition typically does not predispose individuals to particular courses of action. However the authors claim that people's cognition do guide and give meaning to their behaviours, suggesting implications of certain actions, making events meaningful in terms of what people seek and seek to avoid, thus enabling them to set goals and enact behaviours to achieve them.

Such cognitive perspectives are not new in IS research. For example, Orlikowski and Gash (1991) argue that it is important to understand such cognition as it has an influential effect on an individual's acceptance of the technology. This position is resounded by a relatively small, but growing number of IS researchers (see Hunter 1997; Barrett 1999; Davidson 2002; Davidson and Pai 2004; Lin and Silva 2005). Focusing on people's cognition, several IS researchers (Hunter 1997; Lee and Truex 2000; Rugg, Eva et al. 2002; Tan 2003) adopt George Kelly's Personal Construct Theory (PCT) (Kelly 1932; Kelly 1955; Kelly 1969) in their work. Kelly is one of the first psychologists to suggest that in order to understand human behaviour one should first try to understand how people perceive and interpret their social and physical world. He proposed a cognitive theory, which accounts for human individuality in terms of the unique processes that enable people to understand and interpret their world. According to Kelly, human beings are analogues to scientists in that they formulate hypotheses about reality and use these hypotheses to predict events (Brunas-Wagstaff 1998).

Several IS researchers claim that Kelly's theory provides a powerful analytical framework to explore the cognitive dimensions of ISDD activities (see Hunter 1997; Lee and Truex 2000; Rugg, Eva et al. 2002; Tan 2003). However, these researchers employ PCT as a research technique (e.g., Repertory Grid and Cognitive Mapping). Repertory grid and cognitive mapping are methodological extensions of PCT and IS research in this area seems to be mainly preoccupied with these techniques rather than applying PCT. 
Kelly's PCT is much more complex than its methodological extensions. Arguably PCT is a very useful framework for making more visible what lies below the surface of human problems in organisations (see Cornelius 2003; Robertson 2003). Research shows that there are many successful stories in which Kelly's approach is applied to understand people's reactions to new situations using a cognitive approach. Although the majority of such cases are observed in therapeutic settings, there are some examples from organisations as well (see Fransella and Thomas 1988; Dalton and Dunnett 1992; Winter 1992; Viney 1996; Houston 1998; Neimeyer 2003; Winter 2003).

Consequently this paper employs PCT as a theoretical lens to understand the clinicians' reluctance to accept and use new IT systems in the NHS. A main aim of this research is to explore why such reluctance occurs. The approach used in the study departs from earlier approaches in IS research (see Keen 1981; DeSanctis and Courtney 1983; Markus 1983; Joshi 1991) which predominately focus on people's behaviour to understand the 'reluctance'. The paper suggests that cognition plays an important role in explaining the nature of clinicians' reluctance to accept and use new IT systems in the NHS. In the following section a brief introduction to Kelly's PCT is presented along with an outline of how PCT was adopted in this research as an analytical lens. The paper then illustrates the research approach discussing the empirical basis for the work. An analysis and interpretation of empirical data are then provided. Finally implications of the research are presented.

\section{A BRIEF INTRODUCTION OF KELLY'S PCT}

The philosophical foundation of PCT is constructive alternativism. Constructive alternativism assumes that there is a world out there, which exists and is in continual motion. Each individual creates his/her own ways of viewing this world. Therefore he/she constructs his/her own version of this world. His/her view of the world may be similar or different to views of others, but he/she assumes that his/her view represents the true reality. However, constructive alternativism claims that there is a range of alternative ways of constructing reality for the individual (Dalton and Dunnett 1992). 
Here Kelly is not saying that any way of construing is possible. When he says there are alternative ways of looking at any event, he is talking of potential ways (Fransella and Dalton 2000).

Kelly argues that an individual constructs his anticipations using his past experience. If these anticipations or predictions work out in practice, then for an individual the assumptions behind those predictions will be incorporated into his psychological system. On the other hand, if the assumptions do not work out, then re-evaluation of those assumptions will take place. An individual tests and retests these assumptions continuously and finally validates them. These validated assumptions will be stored in the individual's psychological system as "personal constructs". Kelly refers to personal constructs as "transparent templates". He claims that an individual places them on the world and that they guide a person's perception and behaviour. These personal constructs are not just floating around and unconnected; rather they are connected to each other to form a 'construct system'. The central notion here is that individuals respond to the same situation in very different ways as they have different constructs (Kelly 1963).

However Kelly stresses that such differences in constructs do not stop people understanding each other. If one is ready to elaborate his constructs related to a particular event in order to allow new matters to be considered, then one can understand how another person uses their own constructs in relation to the same event, in order to interpret their own experience. With such understanding one can, not only comprehend the history of another person's behaviour, but also make some predictions about how the other person is likely to behave in a given situation (Adams-Webber 2003).

So far the discussion has been concerned with an individual, but the same argument can be applied to groups within organisations. In relation to this, Kelly (1932) addresses the issues of groups and comes up with the idea of a "super-pattern". He argues that personal constructs of individuals in each group make up the sub-patterns of that group which fit into the super-pattern of the group. The notion that a group of individuals share their ways of construing is the outcome of this idea. It makes sense to claim that individuals in a group share constructs and group constructs (henceforth, 
the term group personal constructs will be used to describe super-patterns). Consequently many researchers have used PCT at the group level (see Dunnett and Llewelyn 1988; Fransella, Jones et al. 1988; Tan, Gallupe et al. 2001; Tan 2002; Robertson 2003).

Drawing on the theory of PCT, which has been briefly described in the above section, we argue that when the key stakeholders such as clinicians and IT professionals interact with new IT systems, they use their group personal constructs to make sense of such systems. As a result their acceptance of new IT systems is influenced by their group personal constructs. So understanding how they use their group personal constructs to make sense of ISDD activities is central to explore the clinicians' reluctance to accept and use new IT systems in the NHS. Subsequently this research explored how the group personal constructs of clinician groups and IT groups in the NHS, influence the clinician group's acceptance and usage of new IT systems. In this exploration the research focused on how the groups use their group personal constructs to make sense of new IT systems and their implications on healthcare during the ISDD process.

\section{RESEARCH Methodology}

\section{Philosophical foundation research approach}

This research is based on PCT and its philosophical foundation - constructive alternativism. According to the philosophy of constructive alternativism, in ontological terms, the knowledge gathered by research is not at all mirroring or reflecting an external fixed reality 'out there'. Nor is that knowledge an invention, a product of the researcher's mind. Rather the reality should be understood in terms of interpretation: that is the word Kelly uses in defining constructive alternativism (Gabriele and Nuzzo 2003). Although such assumptions of constructive alternativism parallel the philosophical position of IS interpretive research there are some differences between the former and the latter when they are applied as methodological tools in research. For example some methodological extensions of PCT such as repertory grid are highly instrumental. Some see repertory grid and cognitive mapping 
as providing a sort of psychic $\mathrm{x}$-ray, in which an individual's system of internal constructs can be revealed (see Butt 2004). However, this study takes a position in which such instrumental and scientific characteristics are reduced by using an alternative methodological extension (i.e., laddering). So in essence, constructive alternativism considered in this study is a 'flavour' of interpretive research.

\section{Case Study}

The research was conducted as a case study in a NHS trust. Case study research was considered as an appropriate research strategy for this study as (a) research and theory on the subject are at early formative stage (b) the aim of the research is to explore and explain (c) problems studied are very practice-based (d) organisation's stakeholders' actions and behaviours are important (f) the context of those behaviours and actions are critical (see Markus 1983; Benbasat, Goldestein et al. 1987; Yin 1994; Broadbent and Weill 1997; Klein and Myers 1999) The main research participants in this study were: (a) IT professionals including IT project managers and senior IT managers; and (b) clinicians. The research took place over one and half years in a NHS Trust and included 24 staff (8 IT professionals and 16 clinicians). The research participants were recruited through e-mails, informing them of the study and followup telephone calls were then made if a participant expressed an interest.

Research studies in the NHS involve a number of stakeholders such as doctors, nurses, patients, and managers etc. who raise a number of ethical dilemmas. There are no clear rules for deciding how to deal with these kinds of ethical dilemmas. However, the researcher does have duty to get ethical approval from the local ethics committee before starting the research (Green and Thorogood 2004). Therefore the researcher applied for the ethics committee approval but his first application was unsuccessful. However the researcher managed to get ethics committee approval with his second application addressing the issues of consent and confidentiality. According to the procedures proposed in the application submitted to the ethic committee, the researcher took informed consent from all research participants using the consent form designed by him for this study. The informed consent process helped the researcher to explain what would happen to the research participants during and after the research. It also empowered research participants to make rational judgement 
about whether or not to participate in the research. To make the process of informed consent more effective, the researcher developed a research participants' information sheet, which provided a brief outline of the research including issues of confidentiality. Hence it was explained to the research participants that the information gained from the research would not be disclosed in other settings inside or outside the research site. They were also informed that the identity of the research site and research participants (i.e. name, their position, gender and department) would be protected.

The two local projects suggested by the NHS Trust for this study are:

- Medical Record Management system

- Outpatient Electronic Letter (OEL)

These projects are an integral part of the Trust's IT strategic plan which is shaped by the NPfIT (details of the projects are provided in the Appendix).

\section{Methods of data collection}

This research employed non-participative observations, review of documentation, and semi-structured interviews with key research participants. The data were collected from interviews and observations were recorded in field notes.

During the non-participative observations, the researcher observed how the project work associated with ISDD activities was achieved. The observations involved: (1) shadowing the project managers as they conducted their daily activities; (2) observing internal IT departmental meetings where progress of IT projects, issues and concerns were discussed; (3) observing project managers' meetings with clinicians where issues and concerns about development and usage of IT systems were discussed; (4) observing training sessions for clinicians conducted by Local Service Providers (LSPs); (5) presentations/product demonstrations by LSPs to clinicians and IT personnel; (6) presentations/product demonstrations by project managers to clinicians; (7) clinical requirement gathering sessions by project managers and some LSPs.

The main objectives of the interviewing were to elicit personal constructs from the research participants. The researcher used semi-structured interviews with the 
laddering technique. Hinkle (1965) who worked in clinical psychology within the context of PCT, developed laddering as a means of eliciting personal constructs in a simple and systematic way. It is in the process of laddering that a researcher becomes close to core constructs of research participants. Core constructs are central to an individual's view on events and situations occurring in their social world (see Stewart and Stewart 1981). Laddering also provides some structure to the interview in a sensitive way (Fransella 2003). Laddering is performed asking a series of 'why' questions. These 'why' questions are repeated until it is not possible to go further upwards. A dialogue from an interview carried out using laddering is provided in Appendix 2

Laddering has been used in some areas in the IS field. For example it has been used in knowledge acquisition for expert systems (Rugg and McGeorge 1995) and requirements engineering (Maiden and Rugg 1996). Although the underlying concept is the same, many researchers use slightly different versions of the approach, in order to suit the different purposes for which it is being used (Rugg, Eva et al. 2002). The version used in this research is the one described by Dalton and Dunnett (1992).

Documents were used in this research to fill the gaps of interviews and observations. These documents involved: (1) detailed design documents of IT systems including requirements; (2) business plans of projects; (3) post-implementation reports; (4) minutes of meetings that took place between the IT sector and key stakeholders; (5) documentation of tracking of issues and problems related to projects. The researcher copied these documents with permission from the research participants.

\section{Methods of data analysis}

The analysis of data was done by single researcher. Thematic content analysis was used to analyse the recorded data. Thematic content analysis is an approach aimed at extracting desired information from qualitative data, such as field notes or documents, by systematically and objectively identifying specified characteristics of the data (Green and Thorogood 2004). The aim of this approach is to be systematic and analytic, but not rigid. This method can reduce a large body of qualitative data to a 
smaller and more manageable form of representation (Smith and Judd 2000). The analysis of data, using thematic content analysis was employed to elicit group personal constructs from the IT and clinician groups. In this analysis the data (observations and interviews) were separated into two groups, considering whether they reflected interpretations or actions of the clinician group or IT group. Then each set of data was analysed, using the following steps (Data was analysed to provide a synthesised view across projects, as most of the research participants were involved in all the projects).

\section{Step 1}

The field notes from the observations were divided into two samples. These two samples were selected randomly and not by settings (e.g., type of meetings) or events (e.g., type of IT projects). Then the first sample of field notes was read several times. During the process of reading, the research objectives were revisited to understand what was in the data. The reading was not confined to literal content. During the reading the researcher annotated the data. This involved making annotations about field notes (i.e., 'memos'). The memos were written in the margin of the same paper where field notes were recorded and helped to provide a more detailed description of the data. Using these memos, the data was read interpretively and reflexively developed a construction of the meaning of the data while continuously compared interpretations with the research participants' version (considering the context in which the data was generated). This interpretive and reflective reading enabled the researcher to sense and to identify initial themes in the first sample of data.

\section{Step 2}

At this stage the researcher compared the themes identifying similarities and differences. Then the researcher spliced those similar themes and rewrote them more accurately. He also verified them by reading the field notes again to see if these themes were included. Consequently all initial themes were listed in such a manner that maximised the differentiation of the themes.

\section{Step 3}

The themes identified in the previous step were revived and presented with thematic codes. Boyatzis (1998) suggests that a good thematic code is one that captures the 
qualitative richness of the phenomenon being studied. He claims that good thematic code should have three elements:

- A label (i.e., a name).

- A definition of what the theme concerns (i.e., the characteristic or issue constituting the theme).

- A description of any qualifications to the identification of the theme (i.e., indicators of the theme).

Following the above guidelines, thematic codes were developed for every theme in the list. These codes were applied to the remaining data in the second sample while looking for new codes. Then the researcher refined the codes and applied them to both samples. This iterative process finally generated eight coded themes (see Appendix 2 for initial and final themes). An example of the thematic codes is shown in Table 1.

\begin{tabular}{|l|l|l|}
\hline $\begin{array}{l}\text { Label of } \\
\text { the theme }\end{array}$ & Definition & Indicators \\
\hline $\begin{array}{l}\text { Ineffective } \\
\text { design of IT } \\
\text { systems }\end{array}$ & $\begin{array}{l}\text { The clinician group } \\
\text { describes how proposed } \\
\text { IT systems would not } \\
\text { perform well in the } \\
\text { clinical setting }\end{array}$ & $\begin{array}{l}\text { Code when the clinician group says: data entry and retrieval is } \\
\text { difficult, navigability within screens is difficult, there are lack of icons } \\
\text { and graphical interfaces, the IT group has lack of understanding of } \\
\text { clinical environment (noise level, distractions by patients and staff, } \\
\text { many temporary clinical and administrative staff, shift patterns, very } \\
\text { busy working patterns), the IT group has lack of knowledge of the } \\
\text { multidisciplinary nature of care practice (multidisciplinary dialogue, } \\
\text { clinical pathways), the IT group has lack of knowledge of formats, } \\
\text { layouts and indexing of care records }\end{array}$ \\
\hline
\end{tabular}

Table 1: Example of Thematic Codes

The research participants did not directly articulate their personal constructs in the events and activities observed by the researcher. However, Moch and Fields (1986) suggest that, as people utilise personal constructs when they produce speech or written materials, it could be possible to work back from these materials to identify 
and describe personal constructs. So the themes elicited by observational data analysis were identified as group personal constructs of the research participants. (see Rugg, Eva et al. 2002) .

\section{Step 4}

At this stage, the thematic content analysis discussed in Steps 1, 2 and 3 were performed on the results of interviews with laddering (see Rugg, Eva et al. 2002). In order to validate the group personal constructs elicited from this exercise, such constructs were compared with group personal constructs elicited from the observational data. This comparison enabled the researcher to look for collective personal constructs, which were related although they had different labels, from each data set. Those related group personal constructs were combined and labelled appropriately. However, this comparison showed that some constructs from the interview data were substantially different to the constructs from observational data.

\section{Step 5}

The documents were analysed and group personal constructs were elicited by following the activities discussed in Steps 1, 2, and 3. These constructs were compared with the list of constructs elicited in Step 4. The aim of this comparison was not to generate new group personal constructs, but to confirm the reliability and validity of the list of constructs developed in Step 4 and to consolidate them.

This iterative analysis helped the researcher to identify a set of group personal constructs of clinician and IT groups. 


\section{Findings}

A total of four salient group personal constructs, which have significant difference across the groups, were found from the data. These four group personal constructs are listed below.

1) Design of IT systems

2) Impact of IT systems on clinical activities

3) Clinical ownership of the IT projects

4) Clinical value of the IT systems

The above group personal constructs are discussed in detail in the following sections.

\section{1) Design of IT systems}

\section{Clinician Group's Group Personal Construct: Design of IT systems}

This construct is related to assumptions and expectations that the clinician group had about the design of IT systems in the Trust. The clinicians drew on their past experiences with IT systems in their clinical activities in order to construe the design of the proposed IT systems. Their construing predicted that the proposed systems were not properly designed and they would have difficulties in using them.

The clinicians mentioned that the timely and accurate transfer of clinical information into computers was the most difficult and time consuming step they took when using the current IT systems. The reason being they had to select appropriate words or phrases from menus or lists on the systems rather than free-form text. They claimed that data entry and retrieval could sometimes be extremely complicated as it involved remembering the sequence of tasks through command names and menu options. As a result some clinicians spent a long time learning how to use a particular system. Their unpleasant experiences with the current systems shaped their group personal 
constructs through which they perceived the proposed IT systems as too complex to handle:

"I don't like going through several sub menus to find what I want. When a patient is sitting in front of me, I have to locate necessary information as quickly as possible. Otherwise, I won't have enough time to talk to him. I have seen the demonstration of OEL (Out-patient electronic discharge letter) last week. I think it is going to give us the same problems we are having now... it's too complex; you have to do too many clicks. Can't they (IT people) make it much simpler?"

\section{Clinician}

The construct related to the design of IT systems also includes the clinicians' assumptions about the IT group's understanding of current clinical work practice. The clinician group's previous experiences have shown them that the developers do not have a proper understanding of their clinical needs. For example, the main purpose of the medical record system is to facilitate patient care. To fulfil this purpose it should have a summary of patients' medical/social history, clinical observations, diagnostic conclusions and treatment plans by which clinicians can communicate with other clinicians regarding patient care. Clinicians believed that accessing these records, in a timely manner, is vital for ensuring continuity of care during a patient's hospitalisation. So the construct related to design of IT systems influenced them to anticipate that the importance of local clinical needs would not be understood by the IT group when developing and implementing the proposed systems:

"Paper medical records have format, layout and other textual features. These are critical to our clinical practice because they help us to search, record and access patients' clinical and other information. This proposed scanned medical record system does not seem to have those features.... Indexing is not sufficient... for example, there is no proper indexing for out-patient notes, in-patients notes, test results etc. So searching those records will take considerable time. I do not think this system can be improved to include the features and accessibility to the records, in paper medical records."

Clinician 


\section{$\underline{\text { IT Group's Group Personal Construct: Design of IT systems }}$}

The IT groups construed their anticipation about the proposed IT systems by using their past experience with the clinicians in the ISDD environment, their general knowledge and experience with IT, and the knowledge of the proposed systems gained from the LSPs. Their construing showed that design and features of proposed systems would be fit for their use in the clinical setting.

The IT group mentioned that patients, who are seen over months or years by many clinicians and may be subject to a number of medical interventions over the course of the treatment period, often suffer from multiple diseases. As a result clinical data involve different observations carried out by several clinicians at diverse points in time and the clinicians interpret the data in different ways. So the IT group believed that the different interpretations and the lack of a standardised vocabulary in medicine are particularly problematic when they wish to aggregate data recorded by multiple health professionals. In addition to these problems many clinicians requested free text data entry although interpretation of free text creates additional challenges as computers have great difficulty in the storage, retrieval and management of this kind of data. So the IT group assumed that with the above mentioned complexities and other difficulties imposed by shared or multidisciplinary care, the proposed systems had an acceptable level of user interface and that they were not overly complex:

\footnotetext{
"Healthcare is such a complex business. Many professionals are involved with it and they use different terminologies. At the point of care, all relevant information should be available and it should be meaningful to the particular clinician. So it is impossible to put everything in a single or few screens.... Again if a screen is overstuffed with information very little empty space remains and that overstuffed screen can be intimidating to clinicians, making it difficult for them to pick out specific information at a glance. So, relocating secondary information to the other screens and using hierarchically nested menus to choose them is the most appropriate way to solve the problem."
}

IT person 


\section{2) Impact of IT Systems on Clinical Activities}

\section{Clinician Group's Group Personal Construct: Impact of IT systems on clinical}

$\underline{\text { activities }}$

This construct helped the clinician group to make assumptions about how the proposed IT systems would influence the clinical activities. Many of the clinicians thought that the rigid structures in the current systems subdued their thought processes regarding particular patients when they were documenting the patient's medical details. In addition to these problems, entering all data by making choices from structured menus lead to a reduced level of interaction with patients. Although the clinicians have yet to use the proposed systems, their past experiences with the existing systems have led them to think the proposed systems may have a detrimental effect upon the quality of care:

"Most of the systems we use here do not fit into our care practice. When we are using these systems, we are trying to put the complex clinical practice into the systems. But systems can't accommodate it, as the systems are not sophisticated enough... My point is that the OEL won't be able to produce a discharge summary, which gives the full picture of the patient's problem. The patient's GP will see the partial view of his problem... I mean psycho-social aspects of care are going to be absent. I think GPs and other health professional in the community should have a whole picture of the patient's problem, otherwise the patient won't receive the right care from the service."

\section{Clinician}

"The OEL seems to demand very structured data entry. With our experiences with other systems, this kind of structured data entry can disrupt a doctor's thinking process, as we have to go to many different fields in many different screens, when doing a discharge summary. The end result will lose richness and details of clinical information, which is vital for the health professionals, who organise future care for the patient after we discharge him."

Clinician

The construct related to the impact of IT systems on clinical activities is also shaped by the experiences related to the security and confidentiality of the existing systems. 
Security and confidentiality with respect to IT systems within the trust have been big concerns amongst the clinicians. Although privacy-enhancing functions were incorporated into the existing IT systems, clinicians still believe that the possibility exists for an outsider to access electronic patient information. The clinicians also expressed their concern about confidentiality of electronic clinical information systems. They said that anyone with access to the existing systems could potentially view all the information it contains, irrespective of whether it was relevant to their practice. So the clinicians anticipated that they would have the same problems with the proposed systems:

"We have very sensitive clinical information as we are dealing with patients that are HIV positive. Our patients don't want other people to know that they have got HIV. All our data is stored in our departmental system. Nobody can access it except three of us. It is not integrated with other systems. I know by experience that IT systems in the Trust can't be trusted. They can't provide extra security for our highly sensitive data. They don't apply different levels of protection to the different parts of our patient's record...I mean we need additional protection, but OEL will not have it because it will be integrated with other systems. If some parts of our patients' medical records are passed to a third party such as insurers, our patients will take serious legal action against us."

Clinician

\section{IT Group's Group Personal Construct: Impact of IT systems on clinical activities}

The IT group's personal construct related to the impact of IT systems on clinical activities shows that the group assumed that the proposed systems have many important functions which would contribute to improving the quality of care of patients, including: (1) more complete, more accurate, readable, better structured, and integrated clinical information, which is presented to the clinicians when needed for decision making, (2) direct access and instant updates to such information at multiple locations at any time, (3) fewer dangerous medical errors (e.g., drug errors) resulting from clinicians' poor handwriting, and (4) the ability to produce better reports and capability to analyse huge amounts of structured clinical data for clinical research purposes. 
The IT group believed that the clinicians could harvest the benefits of these functions in their consultations with patients and consequently improve the quality of care. However, according to the IT sector, the clinicians are reluctant to use the proposed systems due to a few shortcomings imposed by limitations of the technology (e.g., less flexible data bases in OEL, low level of readability of handwriting due to inadequate resolution in scanned medical record system). So the IT group predicted that the proposed systems could improve the quality of care if the clinicians were willing to use them without emphasising some problems attached to the new systems and some of their unpleasant experiences with the old systems:

\begin{abstract}
"The clinicians have a lot of benefits. If they want to get those benefits they have to make their minds up to use the systems ... Some of them keep complaining of the database. I think the application strikes a good balance between a flexible database and efficient functions for consultation and data entry. The structure and functionality are strongly related. If you want flexibility you are going to lose some of the functionality. The clinicians have to be more optimistic...."
\end{abstract}

IT person

The construct related to the impact of IT systems on clinical activities is also influenced by the IT group's knowledge of cryptographic technologies and their capabilities. The IT group mentioned that making clinical information readily available for clinical purposes creates opportunities for access by many clinicians and other users and might pose a threat to the security and confidentiality of this information. In response to this issue the IT group has been trying to build systems that strike a balance between increasing information access and security/confidentiality of clinical information. In such a process the users are authenticated through a positive and unique identification process, such as name and password combination. The authenticated user is authorised within the system to perform only certain actions appropriate to his or her role in the Trust. For example, when using the OEL, medical secretaries are not allowed to electronically send discharge letters to GPs without having digital signatures from relevant medical consultants. Strong authentication and authorisation control, which depends on 
cryptographic technologies, is employed to protect clinical information and data that are stored and are transmitted over the networks.

The IT group mentioned that strong authentication and authorisation control leads to important services in addition to exchange of sensitive information, such as provision of digital signatures (certifies authorship), content validation (indicates the contents of a medical record have not been changed), and non-repudiation (indicates that an order such as a medication order received cannot be rejected). Consequently the IT group believed that IT systems in the Trust are much more secure than paper-based systems. However they argue that the majority of clinicians do not have the competence to understand the capability of cryptographic technologies to protect the security and confidentiality of clinical information. According to the IT group this lack of knowledge and understanding of cryptographic technologies make the clinicians worry unnecessarily about the security and confidentiality of clinical information:

“Anybody who disguises in a white coat (doctor's uniform) can go into a clinic and disappear with paper records (clinical notes). Our systems are much more secure than old paper records. The systems are secured by two keys...Can they (the clinicians) understand it? No..."

IT Person

\section{3) Clinical ownership of the IT projects}

\section{Clinician Group's Group Construct: Clinical ownership of the IT projects}

This construct reflects the assumptions and predictions about the clinicians' involvement in ISDD activities. The clinicians' assumptions and predictions were strongly influenced by their previous experience with the IT sector in the ISDD environment. Such experience shaped the above construct, which led the clinicians to believe that their role in the development and delivery of proposed systems would be limited.

Based on previous experience, clinicians have noticed that their role in IT projects was very limited. However, a significant number of clinicians are more than willing to 
participate in ISDD activities. Their role, in the past, was confined to defining their clinical requirements to the projects managers and LSPs and attending product demonstrations. For example, during the requirements gathering phase, clinicians were asked to provide the functional requirements (i.e., what the system should do to carry out clinical activities), but they did not have enough opportunity to discuss nonfunctional requirements (i.e., what constraints there are on the systems and their developments). The clinicians believed that these non-functional requirements are equally important as they refer to the circumstances in which the system is expected to operate. First is the physical environment, such as how many patients are waiting to see the doctor, noise level and distractions in clinicians' work environment. The second is the social environment in which collaboration and coordination of clinical work takes place.

"Attending the product demonstrations, agreeing to be interviewed about our clinical needs and so on is not real involvement. That is pseudo-involvement because we are not playing a very active role... all the big decisions related to projects are taken by management and IT. We are left out to deal with only minor decisions... These are not just IT projects but clinical projects too... Although IT people have more expertise in technical matters, we have the expertise in the application of the systems in the clinical areas...We have seen many systems which did not work at all in clinical settings"

Clinician

"It is very difficult for us to explain what we are doing in the clinical setting or how we deal with exceptional circumstances (emergencies). So it is unlikely that they (IT sector) have got a full picture of our requirements and issues. They have to spend some time with us as we go about our day to day clinical work to understand the real problems we face... Not many IT people would like to do that. So, if they want to see the bigger picture they have to use one of us to bring in those issues to the project team on a daily basis... I mean they need to create roles for clinical representatives from every clinical speciality in the Trust, which would be affected by the new systems."

Clinician 
IT Group's Group Construct: Clinical ownership of the IT projects

This construct was formed by the IT group's understanding of clinicians' capabilities and knowledge of IT in the ISDD environment. The IT group acknowledged that involving clinicians in IT projects would be beneficial as the clinicians can bring clinical knowledge to the project team. However, they thought that most clinicians do not possess adequate technical skills to take a higher role in the development process. For example, some of the senior nurses did not have fundamental understanding of computers and provided a limited contribution to the design. As a result the valuable time of the IT project team and LSPs that could have been used on improving system design was allocated to explain computer basics. For this reason the IT group assigned set roles for the clinicians. For example, the clinicians' role included attending requirement definition meetings, evaluating prototypes at product demonstrations and so on. However, the clinicians were unable to articulate their clinical needs on their own and some clinicians' requirements for customisation were too specific or complicated and thus not readily transferable to an end product. As a result, the IT group was very involved in determining functionality, identifying ways to improve system interface and prioritising requirements of the proposed systems. Using this construct they believed that the clinicians' involvement was vital for the success of the IT projects, but the clinicians could only play a limited role in ISDD activities.

\section{4) Clinical value of IT}

\section{Clinician Group's Group Construct: Clinical value of IT}

This construct is related to assumptions and expectations that the clinician group had about the clinical value of the proposed systems. The clinicians drew their assumptions about how IT was used in the Trust and anticipated that the proposed systems would not be able to increase the productivity of clinical practice. They noticed that paper-based systems were more efficient than the proposed systems. However their knowledge and understanding of IT applications in a global healthcare environment helped them to believe that if the proposed systems were embedded with features like decision support, such systems would be much more productive. 
The clinicians stated that they had considerable difficulty in dealing with the uncertainties associated with diagnosing and treating their patients. Although the clinical data is available on the systems, analysing the data to determine the medical explanation for the patient's symptoms (diagnosis) is challenging and takes a considerable amount of time. The clinicians mentioned that the diagnostic process, which includes deciding which question to ask the patient, what tests to order, and what procedure to perform, is equally challenging and time consuming.

The clinicians considered that a good clinical judgement is based much upon a clinician's experience in his speciality and his ability to reason effectively using available clinical information. However, the clinicians thought that if the proposed IT systems were embedded with clinical decision support features to help them process clinical data in order to make decisions regarding diagnosis, diagnostic processes and treatments, their work would be much easier. Therefore the systems can improve the efficiency and productivity of their clinical practice. As a result the clinicians assumed that these systems would not radically transform the existing clinical tasks based on the paper-based systems and produce previously impossible outcomes to improve clinical effectiveness:

"Our work vastly relies on information. We have a variety of information needs at the point of care ... What medication is the patient currently taking? What are the side effects or allergic reactions of the new medication I am going to prescribe? Is the new medication I am prescribing going to interact with the medication my patient is already on? The paper-based systems can't help us to find answers for all of these questions. It has its own limitations...I know it is our responsibility to check everything before making decisions at the point of care, but mistakes could happen in this busy world ... Current practice relies far too heavily on the memory of the doctor. If a prompt would appear in a smaller screen on the computer when my patient is allergic to the new medication and alert me if the new medication interacts with the medication my patient is currently taking, my work would be much easier. But unfortunately our systems don't have these luxuries. I don't think the IT (the IT sector) would bolt that kind of help to the "scanned medical record system."

Clinician 
The clinicians stated that they were not resistant to new technology as they had embraced many new medical technologies (e.g. magnetic resonance imaging, mammography) without any hesitation. They had willingly accepted such technologies as they were accurate, reliable, and flexible enough to carry out their clinical work in a more effective and efficient manner. So they thought that those technologies added value to the clinical practice and patients got the ultimate benefits. In contrast, they pointed out that existing or proposed IT systems in the Trust do not have adequate strength to yet outweigh the advantages of the paperbased systems in use. For example, paper records can easily be carried around, have free text reporting, do not demand special skills to capture clinical information etc.

According to the clinicians, although there are many functions incorporated in the IT systems, those functions cannot be carried out without increasing the workload of the clinicians. The clinicians argued that they could carry out the same functions using pen and paper with less trouble. They accepted that there are many limitations with paper-based systems which they were using, but the clinicians believed that the electronic equivalent of the paper-based system did not seem to have strength to prove that they can eliminate those limitations without making the clinicians' life harder. As a result the clinicians assumed that proposed systems would not be able to add significant value to their work, which has extensively relied on paper-based systems.

\section{IT Group's Construct: Clinical value of IT}

The IT group acknowledged that decision support features could add some value to the existing and proposed systems such as scanned medical record system and OEL. However, the group believed that developing and maintaining the rule bases that are an integral part of the active decision support systems, is a difficult, expensive and time-consuming task. The IT group thought that validation of decision support systems before their release could be extremely difficult as there is no such thing as the correct answer to a medical problem and there is no evidence that computers can equal the capability of a clinician's thinking process to deal with unanticipated medical situations in health care. Consequently they perceived that decision support features could play a smaller role in improving the clinical value of the proposed 
systems when considering the difficulties, cost and complexities that are involved in developing and maintaining such systems

Although the clinicians still prefer to record clinical details on paper, the IT group explained that paper-based notes have many disadvantages. They argued that in multidisciplinary care, more than one care provider from a different medical speciality is involved in a patient's treatment. In such a setting, a patient's medical record may be unavailable when the clinician needs it, as it may be used by another clinician at another location. When clinicians want to build a complete picture about a patient's health, they may require access to records that are kept by other clinicians of different specialities at different locations.

Besides these limitations the IT group explained that paper-based systems also have disadvantages that are related to clinical research purposes and healthcare planning. The IT group believed that most of these limitations could be overcome by implementing the proposed IT systems such as scanned medical record systems and OEL. For example: 1) electronic medical records in the scanned medical record system and OEL could be accessed from different clinics in the Trust simultaneously as well as by different levels of clinicians; 2) automation in all proposed systems can eliminate problems of illegible handwriting and improve the quality of documentation of care; 3) systems can decrease redundancy of data entry; and 4) OEL can decrease time spent on prescribing and dispensing medication. In addition to these benefits the IT group believed that the proposed systems have high-quality functionality, which could contribute to the quality of care and patient satisfaction. However the IT group strongly believed that the functioning of these systems critically depends on input from the clinicians to make a transition from paper-based systems to computerised workflows. The experience of IT group showed that many clinicians are hesitant to make such a transition:

"The clinicians know that they are having problems locating the patients' records when patients visit the clinic. Sometimes test results are unfilled ... medical records can be accessed by one person in one place at one time. If this is going to continue, the patients will receive poor service that will not promote their satisfaction with their doctors. The OEL and Scanned Medical record systems would increase the 
accessibility and ease of transmission of clinical information... they would speed up the completion of clinical tasks, potentially improved clinical outcomes."

IT Person

\section{DISCUSSION}

The case study clearly shows how the ISDD activities were interpreted differently by clinicians and IT groups as their group personal constructs had significant differences across the groups. The attempt to introduce new systems created a new experience for both groups. New experience was interpreted with reference to the existing group personal constructs by which they made sense of the new IT systems and made predictions about their future application in the clinical setting. Findings show that the clinician group often perceived that the proposed IT systems would have little positive impact on making their job easier or improving patient care; although they mentioned that they were not resistant to new technology as they had embraced many new medical technologies. However, the IT group attempted to persuade the clinician group that the new IT systems had high-quality functionality which could contribute to the quality of care and patient satisfaction in the long, but the clinicians did not see the long term benefits of the systems.

On the other hand, the IT group was unable to understand the importance of the clinicians' views about the new IT systems, as their group personal constructs were significantly different to clinicians' group personal constructs. So when the clinicians tried to express their concerns about new IT systems, they had to deal with people who were already engaged in attributing meaning to the things the clinicians group were talking about. Therefore, the views that the clinician group presented to the IT group had to compete with the assumptions about IT and clinical work that were embedded in the group personal construct of the IT group. As a result the IT group was more interested in the question: what clinical problems would best be solved using latest technology? But they were reluctant to ask the more appropriate question: what is the best way to solve this particular problem that clinicians have in the Trust? To answer this question they would need to learn from the clinicians and sometimes the answer may be that the latest technology is not the solution. 
As mentioned earlier, PCT demonstrates that groups who have different personal constructs tend to construe the same events differently. However, according to PCT if the clinician group elaborates its group personal constructs to allow new matters to be considered, then the clinician group would be able to understand the perspective of the IT group. Such understanding would influence clinicians to accept the new IT systems. However, the clinicians were not ready to elaborate their existing group personal constructs. As a result the clinician group seemed to think that being asked to accept a technology, which was not appropriate for their practice for various reasons, was irrational. On the other hand, the IT group did not show much interest in elaborating their group personal constructs to assimilate new knowledge from the clinicians and appreciate clinicians' concerns. As a result the clinician group thought that the IT group was not taking their views seriously. So during their interactions, both groups did not have proper dialogue while the groups could have participated in a free and creative exploration of each other's views while suspending their own views shaped by their group personal constructs. As a result the clinician group was hesitant to grant credit for good work the IT group had done in the ISDD process and were significantly more negative in their evaluations of the new IT systems. So the clinician group did not wilfully accept the new systems and were reluctant to use them in their practice.

Such reluctance consequently contributed to the difficulties in developing, implementing and using the IT systems in the NHS Trust:

- The planning and design stage of scanned medical record systems lasted for more than a year as the clinician group withheld the commitment needed to continue the project. Eventually the project was abandoned during the last stage of development.

- Despite the reluctance from the clinician group the OEL project persisted for nearly one and half years until the pilot phase was implemented. But the piloting of the OEL quickly grew out of control as the reluctance from the clinician group reached boiling point. As a result the trust decided to cancel the project just before full implementation. 


\section{The contribution of the research}

The main contribution of this research derives from the distinctive approach based on PCT to understand the reluctance of clinicians in the NHS to accept new IT systems and use them in their clinical practice. The argument presented in the paper indicates that such reluctance should be viewed not as deliberate resistance imposed by clinicians, but as their inability of changing their established group personal constructs related to ISDD activities. However, previous research has cautioned managers in healthcare organisations to identify such reluctance as a resistance to change generated by new technology and select change strategies that would minimise or eliminate them (Lorenzi and Riley 2000). The evidence from the organisational research shows that those change strategies would not be successful as they do not pay sufficient attention to the assumptions and expectations embedded in the cognition of organisation members (see Schein 1971; Gioia and Manz 1985; Fiske and Taylor 1991; Schein 1992; Kunda 1999). So this research demonstrates that investigating the assumptions and expectations about new IT systems, deep-seated in the group personal constructs of clinician and IT groups are crucial to understanding the clinicians' reluctance to use new IT systems in their practice. Indeed the contribution of this research has added a body of knowledge to the information systems discipline through extracting knowledge from PCT to refine and enrich the existing body of knowledge in the IS discipline, but paying considerable attention to both the technological and behavioural perspectives emerged from the study.

\section{IMPLICATIONS}

This study mainly focused on identifying the differences in group personal constructs across clinician and IT groups and to show how such differences contribute to the reluctance of the clinicians to accept the new IT systems. Although the paper suggests 
that such reluctance can be reduced if the two groups would elaborate their group personal constructs related to ISDD activities, the paper does not attempt to indicate how this should be done, as both groups seem to cling to their constructs. Thus future research needs to expand this research to better understand how clinicians and IT groups could be helped to elaborate their constructs. However the clinician and IT groups may need an adequate assistance to facilitate the process of elaboration of their constructs as many individuals or groups do not voluntarily elaborate their constructs. Consequently such elaboration of constructs may (1) have potential to alter the perceptions about IT and information systems development and delivery (ISDD) in healthcare settings, each group held (2) also bring each group to new ways of perceiving issues related to ISDD activities that concerned both groups (3) facilitate the groups to have much more meaningful dialogue where the groups could participate in a free and creative exploration of each other's views (4) enable, both groups to be aware of each other's activities, intentions, expectations and limitations and consequently grant each group credit for generous acts taken in the ISDD process (5) help each group to see what the other group is going to provide for them and consequently they could effectively negotiate what they expect, demand and would accept from each other (6) aid the IT and clinician groups to learn from each other to face the challenges of the unknown coming from other group, while remaining experts of their own field. All these activities would eventually reduce the 'reluctance'. Such research would be useful for the successful implementation of new IT programmes in the NHS such as NPfIT, without making costly mistakes.

The study also did not seem to make a sufficient attempt to explore how the political elements in the NHS influence clinicians' reluctance to accept new IT systems. However PCT, the theoretical lens used in this research, does not seem to take these political elements into account, although significantly important in the formation of individual/group personal construct systems. Bannister (2003) claims that PCT is politically egalitarian and it argues for open society in which pursuit of alternatives is central to the way in which people live. Therefore, according to PCT people should be helped to discover their answers - access their own wisdom, creativity and energy to find better alternatives. However PCT does not realize that such better alternatives can be restricted by the limitations imposed by the power structures around them. One has to acknowledge that every theoretical lens has its own limitation. PCT is not an 
exception. However Jasperson et al.(2002) point out that the people in the organizations become powerful (1) possessing structural power which stems from rational legal legitimation of authority to access organizational resources and control them (2) having relationships with powerful people in organizations (3) having expert knowledge and skills which are important to the organization. Furthermore Markus (1983) puts forward that people will be inclined to use a system if they believe it will support their position of power within the organisation. If they think it might cause them to lose power, they will resist. So the power or politics in the NHS is important factors when addressing issues of clinicians' reluctance, as powerful individuals in every stakeholder group could influence others in their group to make decisions related to development, delivery, and usage of new IT systems in the NHS. So future research should employ cognitive and political approach to understand the clinicians' reluctance and explore the actions which need to be taken to reduce such reluctance.

Finally, the main findings in data analysis, need empirical validation and elaboration in other settings as they are generated by only examine a research site. Such examination will yield more complex understanding of the clinicians' reluctance.

\section{CONCLUSION}

The NHS is one of the most complex institutions in the UK where many stakeholders from different disciplines, work together to provide healthcare for people. Consequently the development and implementation of new IT systems in the NHS is a non trivial task as different stakeholders offer different insights and perspectives concerning these IT systems. The success of such systems depends on gaining acceptance from clinicians for them. Therefore to rise to this challenge understanding why clinicians are reluctant to accept new IT systems is important. This paper employs innovative approach based on PCT to deal with the challenge and raises broader questions about the cognitive nature of the ISDD activities which influence clinicians' acceptance of new IT systems. It is hoped that this research will improve our understanding of why developing and implementing IT systems is inherently difficult in the NHS and identify ways to curtail such difficulties. 


\section{REFERENCES}

Adams-Webber, J. (2003). Research in Personal Construct Psychology. International Handbook of Personal Construct Theory. F. Fransella. London, John Wiley and Sons.

Avison, D. E. 2003. 'Is IS an Intellectual Subject?' European Journal of Information Systems: 229-230.

Banister, D. (2003). A brief introduction to Personal Construct Theory. International Hand Book of Personal Construct Theory. F. Fransella. Chichester, John Wiley and Sons: 3-20.

Barrett, M. I. 1999. 'Challenges of EDI Adoption for Electronic Trading in the London Insuarance Market.' European Journal of Information Systems 8(1): 115.

Bartunek, J. M. and Moch, M. K. 1987. 'First-Order, Second-Order, and Third-Order Change and Organization Development Interventions: A Cognitive Approach.' The Journal of Applied Behavioral Science 23(4): 483-500.

Benbasat, I., Goldestein, D. K. and Mead, M. 1987. 'The case research strategy in studies of information systems.' MIS Quarterly 11: 369-386.

Bend, J. (2004). Public Value and E-Health, Institute of Public Policy Research.

Berner, E. S., Detmer, D. E. and Simberg, D. 2005. 'Will the Wave Finally Break? A Brief View of the Adoption of Electronic Medical Recording in the United State.' Journal of The American Medical Information Association 12(1): 3-7.

Bourn, J. (2006). Department of Health, The National Programme for IT in the NHS. London, The National Audit Office.

Boyatzis, R. E. (1998). Transforming Qualitative Information: Thematic Analysis and Code Development. London, Sage.

Brennan, S. (2005). The NHS IT Project. Oxford, Radcliffe.

Broadbent, M. and Weill, P. 1997. 'Improving business and information strtegy alignment: learning from the banking industry.' IBM Systems Journal 32: 162179.

Brunas-Wagstaff, J. (1998). Personality, A Cognitive Approach. London, Routledge.

Butt, T. 2004. 'Understanding, Explanation, and Personal Constructs.' Personal Constructs Theory and Practice 1: 21-27.

Collins, T. (2003). How the National Programme Came to be the Health Service's IT Project. Computer Weekly.

Cornelius, N. (2003). The Struggles of Organizational Transitions. International Handbook of Personal Construct Psychology. F. Fransella. Chichester, John Wiley: 349-357.

Dalton, P. and Dunnett, G. (1992). A Psychology for Living. Chichester, John Wiley.

Davidson, E. and Pai, D. (2004). Making Sense of Technology Frames: Promise, Progress and Potential. Information Systems Research: Relevant Theory and Informed Practice. B. Kaplan, D. Truex, D. Wastell, T. Wood-Harper and J. deGross, Kluwer Academic Publishers: 473-491.

Davidson, E. J. 2002. 'Technology Frames and Framing: A socio-cognitive investigation of requirements determination.' MIS Quarterly 26(4): 329-358. 
DeSanctis, G. and Courtney, J. F. 1983. 'Toward Friendly User MIS Implementation.' Communications of the ACM 26(10).

Dunnett, G. and Llewelyn, S. (1988). Elaborating PCT in a group setting. Working with People. G. Dunnett. London, Routledge.

Fiske, S. T. and Taylor, S. E. (1991). Social Cognition. New York, McGraw-Hill.

Fransella, F. (2003). Some Skills and Tools for Personal Construct Practitioner. International Handbook of Personal Construct Psychology. F. Fransella. Chichester, John Wiley \& Sons.

Fransella, F. and Dalton, P. (2000). Personal Construct Counselling in Action. London, SAGE.

Fransella, F., Jones, H. and Watson, J. (1988). A range of application of PCP within busines and industry. Experimenting with personal construct psychology. F. Fransella and L. Thomas. London, Routledge.

Fransella, F. and Thomas, L. (1988). Experiment with Personal Construct Psychology. London, Routledge \& Kegan Paul.

Gabriele, C. and Nuzzo, M. L. (2003). Kelly's Philosopy of Constructive Alternativism. International Handbook Of Personal Construct Psychology. F. Fransella. Chichester, John Wiley.

Gioia, D. A. and Manz, C. C. 1985. 'Linking Cognition and Behavior: A Script Processing Interpretation of Vicarious Learning.' Academy of Management Review 10(3): 527-539.

Green, J. and Thorogood, N. (2004). Qualitative Methods for Health Research. London, Sage.

Hendy, J., Fulop, N., Reeves, B. C., Hutchins, A. and Collins, S. 2007. 'Implementing the NHS Information Technology Programme: Qualitative study of progress in acute trusts.' British Medical Journal 334(1360).

Hendy, J., Reeves, B. C., Fulop, N., Hutchings, A. and Masseria, C. 2005. 'Challenges to Implementing the National Programme for Information Technology a Qualitative Study.' British Medical Journal 331: 331-336.

Hinkle, D. (1965). The change of personal constructs from the viewpoint of a theory of constrct implications, Ohio State University.

Houston, J. (1998). Making Sense with Offenders, Personal Construct Therapy and Change. Chichester, John Wiley \& Sons.

Hunter, M. G. 1997. 'The Use of RepGrid to gather interview data about information systems analysts.' Information Systems Journal 7: 67-81.

Jasperson, J., Carte, T. A. and Saunders, C. S. 2002. 'Review: Power and Information Technology Research, A Metatriangulation Review.' MIS Quarterly 26(4): 397-459.

Joshi, K. 1991. 'A Model of Users' Perspective on Change: A case of information systems technology implementation.' MIS Quarterly 15(2).

Kaplan, B. 2001. 'Evaluating informatics applications-some alternative approaches: theory, social interactionism, and call for methodological pluralism.' International Journal of Medical Informatics 64: 39-56.

Keen, P. G. W. 1981. 'Information Systems and Organizational Change.' Communications of the ACM 24(1): 24-33.

Kelly, G. A. (1932). Understandable psychology. Franesella PCP Collection. Hertfordshire.

Kelly, G. A. (1955). The Psychology of Personal Constructs, Norton.

Kelly, G. A. (1963). A Theory of Personality: The Psychology of Personal Constructs. New York, Nortan and Company. 
Kelly, G. A. (1969). Clinical Psychology and Personality. New York, John Wiley and Sons.

Klein, H. K. and Myers, M. D. 1999. 'A Set of Principles for Conducting and Evaluating Interpretive Field Studies in Information Systems.' MIS Quarterly 23(1): 67-94.

Kunda, Z. (1999). Social Cognition: Making Sence of People. Cambridge,Mass, MIT Press.

Lapointe, L. and Rivard, S. 2006. 'Getting Physicians to Accept New Information Technology: Insights from Case Studies.' Canadian Medical Association Journal 174(11): 1573-1574.

Lee, J. and Truex, P. 2000. 'Exploring the Impact of Formal Training in ISD Methods on the Cognitive Structure of Novice Information Systems Developers.' Information Systems Journal 10: 347-367.

Lin, A. and Silva, L. 2005. 'The Social and Political Construct of Technological Frames.' European Journal of Information Systems 14: 49-59.

Lorenzi, N. M. and Riley, R. T. 2000. 'Managing Change: An Overview.' The Journal of the American Medical Association 7(2): 116-124.

Maiden, N. A. and Rugg, G. 1996. 'ACRE: A Framework for acquisition of requirements.' Software Engineering Journal 11(3): 183-192.

Markus, M. L. 1983. 'Power, Politics, and MIS implementation.' Comunication of the ACM 26: 430-444.

Moch, M. K. and Fields, W. C. (1986). Developing a Content Analysis for Interpreting Language Use in Organizations. Perspectives in Organization Sociology. S. Bacharach and S. Mitchell. Greenwich, CT, JAI Press.

NAO (2008). The National Programme for IT in the NHS: Progress since 2006. London, National Audit Office.

Neimeyer, R. A. (2003). Personal Construct Psychotherapy and the Constructivist Horizon. International Handbook of Personal Construct Psychology. F. Fransella. Chichester, John Wiley and Sons.

NHS (1998). NHS Executive, Information for Health, An Information Strategy for the Modern NHS 1998-2005, Department of Health.

NHS (2003). NHS Configuration, National Programme for IT, An Interview with Richard Granger and Peter Hutton, Briefing, September, Department of Health.

NHS (2003). NHS Configuration, National Programme for IT, Briefing, August.

Orlikowski, W. and Gash, D. C. (1991). Changing Frames: understanding technological changes in organizations. Cambridge, MA, Massachusetts Institute of Technology.

Paul, R. 2002. 'Is information systems an intellectual subjects?' European Journal of Information Systems 11: 174-177.

Robertson, A. (2003). Making Sense of Group Mind. International Hand Book of Personal Construct Theory. F. Fransella. Chichester, John Wiley: 339-348.

Rugg, G., Eva, M., Mahmood, A. and Rehman, N. 2002. 'Eliciting Information about Organizational Culture via Laddering.' Information Systems Journal 12: 215 229.

Rugg, G., Eva, M., Mahmood, A., Rehman, N., Andrews, S. and Davies, S. 2002. 'Eliciting Information about Organizational Culture via Laddering.' Information Systems Journal 12: 215-229.

Rugg, G. and McGeorge, P. 1995. 'Laddering.' Expert Systems 12: 339-346.

Schein, E. H. (1971). Coercive Persuasion. New York, W H Norton. 
Schein, E. H. (1992). How Can Organization Learn Faster? The Problem of Entering the Green Room, MIT Sloan School of Management.

Schuster, D. M., Hall, S. E., Couse, C. B., Swayngim, D. S. and Kohatsu, K. Y. 2003. 'Involving Users in the Implementation of an Imaging Order Entry Systems.' Journal of The American Medical Information Association 10: 315-321.

Scott, J. T., Rundall, T. G., Vogt, T. M. and Hsu, J. 2005. 'Kaiser Permanente's Experience of Implementing an Electronic Medical Record: A Qualitative Study.' British Medical Journal 331.

Smith, C. P. and Judd, C. M. (2000). Content Analysis and Narrative Analysis.

Stewart, V. and Stewart, A. (1981). Business Application of Repertory Grid. London, McGraw-Hill.

Tan, F. B. 2002. 'The Repertory Grid Technique: A method for the study of cognition in information systems.' MIS Quarterly 26(1): 39-57.

Tan, F. B. (2003). A Framework for Research into Business-IT Alignment: Cognitive Emphasis, Idea Group Publishing.

Tan, F. B., Gallupe, R. B. and Diaz, J. A. (2001). Aligning Business and IT Thinking: A cognitive approach, Dept of Management Science and Information Systems, The University of Auckland, Auckland, New Zealand,

School of Business, Queen's University, Kingston, Ontario, Canada: 1-42.

Viney, L. L. (1996). Personal Construct Therapy. New Jersy, Ablex Publishing Corporation.

Winter, D. A. (1992). Personal Construct Psychology in Clinical Practice; Theory, Research and Applications. London, Routledge.

Winter, D. A. (2003). The Evidence Base for Personal Construct Psychotherapy. International Handbook of Personal Construct Psychology. F. Fransella. Chichester, John Wiley and Sons.

Yin, R. K. (1994). Case Study Research. Thousand Oaks, Sage Publications. 


\section{APPENDIX 1}

\section{Medical Record Management}

Paper medical records are held in several libraries throughout the Trust, with one general library at each of the two large sites and several other departmental libraries. A patient record contains on average 70 sheets of paper and these are made up of:

- Test results

- Letters (including referrals)

- Results

- History sheets

- Nursing notes

- X-Rays and photographs

- Maternity notes (after pregnancy only)

- Discharge summaries

According to the Trust's IT group, the problems and limitations of current system are:

- Lack of availability of records for multiple uses causing clinical risk

- Transport

- Space

- Safety/Security/confidentiality

- Accidental destruction

- Tampering

- Tracking the records once out

- Cost of managing paper based records

To overcome the above difficulties, the top management of the NHS Trust has decided to digitally store all medical records by means of scanning paper notes. The scanned notes will be structured and indexed by document type (e.g. results, correspondence, history sheet, by date, etc). The produced images will be compatible with all relevant trust IT systems (e.g. EPR). The proposed system will be expected to fit with the National Program for IT (NPfIT). 


\section{Outpatient Electronic Letter (OEL)}

OEL is a comprehensive software solution, which generates electronic out patient discharge summaries (discharge letter) and electronically deliver them to the GPs and other appropriate health professionals in the community, with pre-coded data available in XML. This discharge letter intends to provide comprehensive and complete information about the patients as they leave the outpatient clinics, and the patients can be confident that all the most up to date information will be available when they are visiting their GPs. The electronic discharge summary in OEL is designed to be completed during the patient's stay in the clinic so hospital staff and clinicians can start compiling OEL as soon as they are admitted. This tends to remove the time pressure and delays that normally occur at out patient discharge: The clinicians will be able to send the drug prescriptions electronically to the hospital pharmacist and the patients can collect their medication from the hospital pharmacy after the clinic. The drug prescription and dispensing process is managed and controlled, reflecting the lines of authority and responsibility between the clinician and the pharmacist.

The clinicians can enter patient and clinical data using drop down menus and compulsory boxes on the template. The mandatory fields are highlighted ensuring that GPs have all the patient information they need for subsequent after-care. Every individual junior doctor, consultant or other authorised user is given a unique individual password, ensuring security and an audit trail of information accessed. OEL is based on web-browser system and integrated to all clinical systems in the Trust so the clinicians can access clinical /administrative information, from different systems such as radiology, pathology etc. 


\section{APPENDIX 2}

\section{$\underline{\text { Initial Thames }}$}

\begin{tabular}{|c|c|c|c|}
\hline $\begin{array}{l}\text { Label of } \\
\text { the theme }\end{array}$ & Definition & Indicators & Sub themes \\
\hline $\begin{array}{l}\text { Ineffective } \\
\text { design of IT } \\
\text { systems }\end{array}$ & $\begin{array}{l}\text { The clinician group } \\
\text { describes how proposed } \\
\text { IT systems would not } \\
\text { perform well in the } \\
\text { clinical setting }\end{array}$ & $\begin{array}{l}\text { Code when the clinician group says: data } \\
\text { entry and retrieval is difficult, navigability } \\
\text { within screens is difficult, there are lack of } \\
\text { icons and graphic interfaces, the IT group has } \\
\text { lack of understanding of clinical environment } \\
\text { (noise level, distraction by patients and staff, } \\
\text { many temporary clinical and administrative } \\
\text { staff, shift patterns, very busy working } \\
\text { patterns), the IT group has lack of knowledge } \\
\text { of multidisciplinary nature of care practice } \\
\text { (multidisciplinary dialogue, clinical } \\
\text { pathways), the IT group has lack of } \\
\text { knowledge of formats, layouts and indexing } \\
\text { of care records, the clinicians are not } \\
\text { competent enough to use proposed systems } \\
\text { as there is no sufficient training }\end{array}$ & $\begin{array}{l}\text { - Complexity of } \\
\text { the applications } \\
\text { - IT group's } \\
\text { understanding of } \\
\text { the local clinical } \\
\text { environment } \\
\text { - IT group's } \\
\text { understanding of } \\
\text { current clinical } \\
\text { work } \\
\text { IT competence } \\
\text { of the clinicians }\end{array}$ \\
\hline $\begin{array}{l}\text { Negative } \\
\text { impact of IT } \\
\text { systems on } \\
\text { clinical } \\
\text { activities }\end{array}$ & $\begin{array}{l}\text { The clinician group } \\
\text { describes that the } \\
\text { proposed IT systems will } \\
\text { have a detrimental effect } \\
\text { on their practice }\end{array}$ & $\begin{array}{l}\text { Code when the clinician group says: the } \\
\text { clinicians would not be able to provide } \\
\text { quality care using proposed systems, the full } \\
\text { picture of patient care cannot put into the } \\
\text { rigid structures of the proposed systems, the } \\
\text { structures of the IT systems would demand } \\
\text { irrelevant clinical information, the structures } \\
\text { of the IT systems would request little relevant } \\
\text { clinical information, structured data entry in } \\
\text { proposed systems would disrupt doctors' } \\
\text { thinking process, the clinician would not be } \\
\text { able to access to patient data as the systems } \\
\text { do not talk to each other, outsiders might } \\
\text { access to patients information on the IT } \\
\text { systems, staff shares pass words as there are } \\
\text { many temporary staff, sensitive data on the } \\
\text { proposed systems would be able seen by any } \\
\text { one with access to the systems }\end{array}$ & $\begin{array}{l}\text { - Security and } \\
\text { Confidentiality of } \\
\text { clinical } \\
\text { information }\end{array}$ \\
\hline $\begin{array}{l}\text { Limited } \\
\text { clinical } \\
\text { ownership of } \\
\text { the IT } \\
\text { projects }\end{array}$ & $\begin{array}{l}\text { The clinician group } \\
\text { describes that their role } \\
\text { in the development and } \\
\text { delivery of proposed } \\
\text { systems would be } \\
\text { limited }\end{array}$ & $\begin{array}{l}\text { Code when the clinician group says: the IT } \\
\text { group and top management decide and } \\
\text { initiate funding for the projects, the clinicians } \\
\text { do not have enough opportunity to discuss } \\
\text { non functional requirements, their role is } \\
\text { limited to defining clinical requirements and } \\
\text { attending the product demonstrations, there is } \\
\text { no big role for clinical representatives in } \\
\text { ISDD activities, they were not involved in the } \\
\text { procurement process, they were not consulted } \\
\text { during the procurement process, they are the } \\
\text { best people to decide the performance of } \\
\text { LSPs }\end{array}$ & $\begin{array}{l}\text { - Clinicians' role } \\
\text { in ISDD }\end{array}$ \\
\hline
\end{tabular}




\begin{tabular}{|c|c|c|c|}
\hline $\begin{array}{l}\text { Limited } \\
\text { clinical value } \\
\text { of IT }\end{array}$ & $\begin{array}{l}\text { The clinician group } \\
\text { describe that proposed } \\
\text { IT systems would not } \\
\text { increase the productivity } \\
\text { of existing clinical } \\
\text { practice }\end{array}$ & $\begin{array}{l}\text { Code when the clinician group says: } \\
\text { analysing clinical data on the systems and } \\
\text { using them to diagnose illness is challenging, } \\
\text { using clinical data to diagnose illness is time } \\
\text { consuming, proposed systems should be } \\
\text { embedded with decision support systems, the } \\
\text { proposed systems should generate prompts to } \\
\text { remind allergic reactions, the proposed } \\
\text { systems should suggest medical tests and } \\
\text { procedures, paper based medical records are } \\
\text { better, proposed systems increase the } \\
\text { workload of the clinicians, paper based } \\
\text { systems do not demand time consuming data } \\
\text { entry and retrieval }\end{array}$ & $\begin{array}{l}\text { - Decision } \\
\text { support systems }\end{array}$ \\
\hline $\begin{array}{l}\text { Effective } \\
\text { design of IT } \\
\text { systems }\end{array}$ & $\begin{array}{l}\text { The IT group describes } \\
\text { that health care is a } \\
\text { complex business and } \\
\text { within that complexity } \\
\text { the proposed IT systems } \\
\text { are properly designed }\end{array}$ & $\begin{array}{l}\text { Code when the IT group describes : the lack } \\
\text { of standardized vocabulary in medicine poses } \\
\text { challenge when designing systems, the } \\
\text { multidisciplinary care pose challenge when } \\
\text { designing systems, complex medical } \\
\text { information can not be put in a single or few } \\
\text { screens, OEL has web browser technology } \\
\text { which is easier to use, systems have good } \\
\text { functionality although they are little complex, } \\
\text { the IT group has good knowledge about } \\
\text { clinical environment, members of the IT } \\
\text { group have been working in the NHS for long } \\
\text { time, the IT group know how the clinicians } \\
\text { work, the clinicians have to abandon outdated } \\
\text { work practices, the clinical practices based } \\
\text { on paper based systems can not be applied } \\
\text { when using systems, IT training available for } \\
\text { the clinicians, the clinicians lack interest in IT } \\
\text { training, existing training programme can } \\
\text { not change clinicians' attitudes towards IT }\end{array}$ & $\begin{array}{l}\text { - Complexity of } \\
\text { the applications } \\
\text { - IT group's lack } \\
\text { of understanding } \\
\text { of the local } \\
\text { clinical } \\
\text { environment } \\
\text { - IT group's } \\
\text { understanding of } \\
\text { current clinical } \\
\text { work } \\
\text { - Lack of IT } \\
\text { competence of } \\
\text { the clinicians }\end{array}$ \\
\hline $\begin{array}{l}\text { Positive } \\
\text { impact of IT } \\
\text { systems on } \\
\text { clinical } \\
\text { activities }\end{array}$ & $\begin{array}{l}\text { The IT group describes } \\
\text { that the proposed IT } \\
\text { systems have better } \\
\text { capability which would } \\
\text { have positive impact on } \\
\text { clinical activities }\end{array}$ & $\begin{array}{l}\text { Code when the IT group says: the systems } \\
\text { can produce better medical reports and fewer } \\
\text { dangerous medical errors, the systems have } \\
\text { direct access and instant updates to medical } \\
\text { information at multiple locations at any time, } \\
\text { the functions of the systems could improve } \\
\text { the quality of care, integrated access } \\
\text { important but the pathology, radiology, } \\
\text { pharmacy, legacy systems make it difficult, } \\
\text { the migration strategy would not be easy as } \\
\text { many old systems belong to different LSPs, } \\
\text { access to information would not be a big } \\
\text { problem if the clinicians change their } \\
\text { attitudes towards IT, the proposed systems } \\
\text { strike a balance between information access } \\
\text { and security, the systems are protected by } \\
\text { public-key cryptography, the systems are } \\
\text { more secure than the paper based systems, } \\
\text { clinicians lack understanding of } \\
\text { cryptographic technologies, the clinicians are } \\
\text { unnecessary worry about security, the } \\
\text { clinicians are not aware of security issues } \\
\text { when using the systems, the clinicians share } \\
\text { pass words, the clinicians have poor pass } \\
\text { word management }\end{array}$ & $\begin{array}{l}\text { - Security and } \\
\text { Confidentiality of } \\
\text { clinical } \\
\text { information }\end{array}$ \\
\hline $\begin{array}{l}\text { Reasonable } \\
\text { clinical } \\
\text { ownership of } \\
\text { the IT } \\
\text { projects }\end{array}$ & $\begin{array}{l}\text { The IT group describes } \\
\text { that involving the } \\
\text { clinicians in IT projects } \\
\text { is a good thing but the } \\
\text { clinicians do not have } \\
\text { adequate technical skills }\end{array}$ & $\begin{array}{l}\text { Code when the IT group says: some clinicians } \\
\text { do not have fundamental understanding of } \\
\text { computers, the clinicians are unable to } \\
\text { articulate their clinical requirements, the } \\
\text { clinicians' requirements are very specific and } \\
\text { can not be transferable to a technical product, }\end{array}$ & $\begin{array}{l}\text { - Clinicians' role } \\
\text { in ISDD }\end{array}$ \\
\hline
\end{tabular}




\begin{tabular}{|c|c|c|c|}
\hline & $\begin{array}{l}\text { to have high degree of } \\
\text { ownership of the } \\
\text { projects }\end{array}$ & $\begin{array}{l}\text { the clinicians waste LSPs' time in meetings } \\
\text { as the clinicians do not have technical } \\
\text { knowledge, the clinicians demand } \\
\text { unreasonable service from LSPs, if the } \\
\text { clinicians play a bigger role they can damage } \\
\text { the relationship the Trust have with LSPs, } \\
\text { higher SLAs are more expensive, need to } \\
\text { have balance between quality and price, the } \\
\text { clinicians can abuse escalation procedures }\end{array}$ & $\begin{array}{l}\text { - Outsourcing } \\
\text { process }\end{array}$ \\
\hline $\begin{array}{l}\text { Good clinical } \\
\text { value of IT }\end{array}$ & $\begin{array}{l}\text { The IT group describes } \\
\text { that the proposed IT } \\
\text { systems would } \\
\text { incrementally improve } \\
\text { the clinical performance }\end{array}$ & $\begin{array}{l}\text { Code when the IT group says: paper based } \\
\text { systems have many disadvantages, paper } \\
\text { medical records can be unavailable when the } \\
\text { clinicians need them, the clinicians may find } \\
\text { difficult to read the paper records, clinical } \\
\text { information may be missing in the paper } \\
\text { records, electronic medical records in the } \\
\text { proposed systems could be accessed from } \\
\text { several difficult clinics in the Trust, the } \\
\text { proposed systems would decrease redundancy } \\
\text { of data, OEL would reduce time spent on } \\
\text { prescribing and dispensing medication, the } \\
\text { proposed systems would increase patients } \\
\text { satisfaction, the transition from the paper } \\
\text { based system to computerised workflow } \\
\text { would be difficult, decision support systems } \\
\text { could add value to the proposed systems but } \\
\text { developing them is difficult and expensive, } \\
\text { validating decision support systems would be } \\
\text { extremely difficult as there is no one correct } \\
\text { answer to a medical problems, decision } \\
\text { support systems can not replace the } \\
\text { experienced clinician }\end{array}$ & $\begin{array}{l}\text { - } \quad \text { Paper based } \\
\text { systems } \\
\text { - Decision } \\
\text { support systems }\end{array}$ \\
\hline
\end{tabular}

\section{Final Themes}

\begin{tabular}{|c|c|c|c|}
\hline $\begin{array}{l}\text { Label of } \\
\text { the } \\
\text { theme }\end{array}$ & Definition & Indicators & Sub themes \\
\hline $\begin{array}{l}\text { Design of } \\
\text { IT systems }\end{array}$ & $\begin{array}{l}\text { The clinician group } \\
\text { describes how proposed } \\
\text { IT systems would not } \\
\text { perform well in clinical } \\
\text { setting }\end{array}$ & $\begin{array}{l}\text { Code when the clinician group says: data entry } \\
\text { and retrieval is difficult, navigability within } \\
\text { screens is difficult, there are lack of icons and } \\
\text { graphic interfaces, the IT group has lack of } \\
\text { understanding of clinical environment (noise } \\
\text { level, distraction by patients and staff, many } \\
\text { temporary clinical and administrative staff, } \\
\text { shift patterns, very busy working patterns), the } \\
\text { IT group has lack of knowledge of } \\
\text { multidisciplinary nature of care practice } \\
\text { (multidisciplinary dialogue, clinical pathways), } \\
\text { the IT group has lack of knowledge of formats, } \\
\text { layouts and indexing of care records, the } \\
\text { clinicians are not competent enough to use } \\
\text { proposed systems as there is no sufficient } \\
\text { training }\end{array}$ & $\begin{array}{l}\text { - Complexity of } \\
\text { the applications } \\
\text { - IT group's } \\
\text { understanding of } \\
\text { the local clinical } \\
\text { environment }\end{array}$ \\
\hline
\end{tabular}




\begin{tabular}{|c|c|c|c|}
\hline & $\begin{array}{l}\text { The IT group describes } \\
\text { that health care is a } \\
\text { complex business and } \\
\text { within that complexity } \\
\text { the proposed IT systems } \\
\text { are properly designed }\end{array}$ & $\begin{array}{l}\text { Code when the IT group describes: the lack of } \\
\text { standardized vocabulary in medicine poses } \\
\text { challenge when designing systems, the } \\
\text { multidisciplinary care pose challenge when } \\
\text { designing systems, complex medical } \\
\text { information can not be put in a single or few } \\
\text { screens, OEL has web browser technology } \\
\text { which is easier to use, systems have good } \\
\text { functionality although they are little complex, } \\
\text { the IT group has good knowledge about } \\
\text { clinical environment, members of the IT group } \\
\text { have been working in the NHS for long time, } \\
\text { the IT group know how the clinicians work but } \\
\text { the clinicians have to abandon outdated work } \\
\text { practices, the clinical practices based on } \\
\text { paper based systems can not be applied when } \\
\text { using systems, IT training available for the } \\
\text { clinicians, the clinicians lack interest in IT } \\
\text { training, existing training programme can not } \\
\text { change clinicians' attitudes towards IT }\end{array}$ & $\begin{array}{l}\text { IT group's } \\
\text { understanding of } \\
\text { current clinical } \\
\text { work }\end{array}$ \\
\hline \multirow[t]{2}{*}{$\begin{array}{l}\text { Impact of IT } \\
\text { systems on } \\
\text { clinical } \\
\text { activities }\end{array}$} & $\begin{array}{l}\text { The clinician group } \\
\text { describes that the } \\
\text { proposed IT systems will } \\
\text { have a detrimental effect } \\
\text { on their practice }\end{array}$ & $\begin{array}{l}\text { Code when the clinician group says: the } \\
\text { clinicians would not be able to provide quality } \\
\text { care using proposed systems, the full picture of } \\
\text { patient care cannot put into the rigid structures } \\
\text { of the proposed systems, the structures of the } \\
\text { IT systems would demand irrelevant clinical } \\
\text { information, the structures of the IT systems } \\
\text { would request little relevant clinical } \\
\text { information, structured data entry in proposed } \\
\text { systems would disrupt doctors thinking } \\
\text { process, the clinician would not be able to } \\
\text { access to patient data as the systems do not talk } \\
\text { to each other, outsiders might access to } \\
\text { patients information on the IT systems, staff } \\
\text { shares pass words as there are many temporary } \\
\text { staff, sensitive data on proposed systems } \\
\text { would be able seen by any one with access to } \\
\text { the systems }\end{array}$ & $\begin{array}{r}\text { Quality of } \\
\text { patient care }\end{array}$ \\
\hline & $\begin{array}{l}\text { The IT group describes } \\
\text { that the proposed IT } \\
\text { systems have better } \\
\text { capability which would } \\
\text { have positive impact on } \\
\text { clinical activities }\end{array}$ & $\begin{array}{l}\text { Code when the IT group says: the systems can } \\
\text { produce better medical reports, fewer } \\
\text { dangerous medical errors, the systems have } \\
\text { direct access and instant updates to medical } \\
\text { information at multiple locations at any time, } \\
\text { the functions of the systems could improve the } \\
\text { quality of care, integrated access important but } \\
\text { the pathology, radiology, pharmacy, legacy } \\
\text { systems make it difficult, the migration } \\
\text { strategy would not be easy as many old } \\
\text { systems belong to different LSPs, access to } \\
\text { information would not be a big problem if the } \\
\text { clinicians change their attitudes towards IT, the } \\
\text { proposed systems strike a balance between } \\
\text { information access and security, the systems } \\
\text { are protected by public-key cryptography, the } \\
\text { systems are more secure than the paper based } \\
\text { systems, clinicians lack understanding of } \\
\text { cryptographic technologies and are } \\
\text { unnecessary worry about security, the } \\
\text { clinicians are not aware of security issues } \\
\text { when using the systems, the clinicians share } \\
\text { pass words, the clinicians have poor pass word } \\
\text { management }\end{array}$ & $\begin{array}{l}\text { - Security and } \\
\text { Confidentiality of } \\
\text { clinical information }\end{array}$ \\
\hline
\end{tabular}




\begin{tabular}{|c|c|c|c|}
\hline $\begin{array}{l}\text { Clinical } \\
\text { ownership } \\
\text { of the IT } \\
\text { projects }\end{array}$ & $\begin{array}{l}\text { The IT group describes } \\
\text { that involving the } \\
\text { clinicians in IT projects } \\
\text { is a good thing but the } \\
\text { clinicians do not have } \\
\text { adequate technical skills } \\
\text { to have high degree of } \\
\text { ownership of the projects }\end{array}$ & $\begin{array}{l}\text { Code when the clinician group says: the IT } \\
\text { group and top management decide and initiate } \\
\text { funding for the projects, the clinicians do not } \\
\text { have enough opportunity to discuss non } \\
\text { functional requirements, their role is limited to } \\
\text { defining clinical requirements and attending } \\
\text { the product demonstrations, there is no big role } \\
\text { for clinical representatives in ISDD activities, } \\
\text { they were not involved in the procurement } \\
\text { process, they were not consulted during the } \\
\text { procurement process, they are the best people } \\
\text { to decide the performance of LSPs } \\
\text { Code when the IT group says: some clinicians } \\
\text { do not have fundamental understanding of } \\
\text { computers, the clinicians are unable to } \\
\text { articulate their clinical requirements, the } \\
\text { clinicians' requirements are very specific and } \\
\text { can not be transferable to a technical product, } \\
\text { the clinicians waste LSPs' time in meetings as } \\
\text { the clinicians do not have technical knowledge } \\
\text { the clinicians demand unreasonable service } \\
\text { from LSPs, if the clinicians play a bigger role } \\
\text { they can damage the relationship the Trust } \\
\text { have with LSPs, higher SLAs are more } \\
\text { expensive, need to have balance between } \\
\text { quality and price, the clinicians can abuse } \\
\text { escalation procedures }\end{array}$ & $\begin{array}{l}\text { - Clinicians' role } \\
\text { in ISDD }\end{array}$ \\
\hline \multirow[t]{2}{*}{$\begin{array}{l}\text { Clinical } \\
\text { value of IT }\end{array}$} & $\begin{array}{l}\text { The clinician group } \\
\text { describe that proposed IT } \\
\text { systems would not } \\
\text { increase the productivity } \\
\text { of existing clinical } \\
\text { practice }\end{array}$ & $\begin{array}{l}\text { Code when the clinician group say : analysing } \\
\text { clinical data on the systems and using them to } \\
\text { diagnose illness is challenging, using clinical } \\
\text { data to diagnose illness is time consuming, } \\
\text { proposed systems should be embedded with } \\
\text { decision support systems, the proposed } \\
\text { systems should generate prompts to remind } \\
\text { allergic reactions, the proposed systems should } \\
\text { suggest medical tests and procedures, paper } \\
\text { based medical record are better, proposed } \\
\text { systems increase the workload of the } \\
\text { clinicians, paper based systems does not } \\
\text { demand time consuming data entry and } \\
\text { retrieval }\end{array}$ & $\begin{array}{l}\text { - } \\
\text { suppocision } \\
\text { support systems }\end{array}$ \\
\hline & $\begin{array}{l}\text { The IT group describes } \\
\text { that the proposed IT } \\
\text { systems would } \\
\text { incrementally improve } \\
\text { the clinical performance }\end{array}$ & $\begin{array}{l}\text { Code when the IT group says: paper based } \\
\text { systems have many disadvantages, paper } \\
\text { medical records can be unavailable when the } \\
\text { clinicians need them, the clinicians may find } \\
\text { difficult to read the paper records, clinical } \\
\text { information may be missing in the paper } \\
\text { records, electronic medical records in the } \\
\text { proposed systems could be accessed from } \\
\text { several difficult clinics in the Trust, the } \\
\text { proposed systems would decrease redundancy } \\
\text { of data, OEL would reduce time spent on } \\
\text { prescribing and dispensing medication, the } \\
\text { proposed systems would increase patients } \\
\text { satisfaction, the transition from the paper based } \\
\text { system to computerised workflow would be } \\
\text { difficult, decision support systems could add } \\
\text { value to the proposed systems but developing } \\
\text { them is difficult and expensive, validating }\end{array}$ & $\begin{array}{l}\text { - } \\
\text { Paper based } \\
\text { systems }\end{array}$ \\
\hline
\end{tabular}




\begin{tabular}{|l|l|l|l|}
\hline & $\begin{array}{l}\text { decision support systems would be extremely } \\
\text { difficult as there is no one correct answer to a } \\
\text { medical problem, decision support systems can } \\
\text { not replace the experienced clinician }\end{array}$ & \\
\hline
\end{tabular}

An Example of Laddering

The medical consultant: The patient's GP will see the partial view of his problem when we are using this electronic letter (OEL)... I mean psycho-social aspects of care are going to be absent. I think GPs and other health professional in the community should have a whole picture of the patient's problem, otherwise the patient won't receive the right care from the service.

The researcher: Why is that?

The medical consultant: My point is that the OEL won't be able produce a discharge summary which gives the full picture of the patient's problem... The system can't accommodate it, as it is not sophisticated enough...I don't think that anybody would use it.

The researcher: Would you use it in your clinic?

\section{The medical consultant: NO}

The researcher: Why?

The medical consultant: .....When we are using these systems, we are trying to put the complex clinical practice into the systems. If we are going to use the OEL we going to have same problems...I mean our practice will suffer (Group Personal Construct-Impact of IT systems on clinical activities). 